\section{( OPEN ACCESS}

\title{
Risk factors for endoscopic sedation reversal events: a five-year retrospective study
}

\author{
Nekisa Zakeri, Sergio Coda, Shelby Webster, William Howson, \\ Andrew $\mathrm{V}$ Thillainayagam
}

\begin{abstract}
- Additional material is published online only. To view please visit the journal online (http://dx.doi.org/10.1136/ flgastro-2014-100460).
\end{abstract}

Department of Gastroenterology \& Hepatology, Imperial College Healthcare NHS Trust, London, UK

\section{Correspondence to}

Dr Andrew V Thillainayagam, Department of Gastroenterology \& Hepatology, Imperial College Healthcare NHS Trust, Room 17 First floor Main Building, Charing Cross Hospital, Fulham Palace Road, London W6 8RF, UK;

a.thillainayagam@imperial.ac.uk

Received 14 April 2014 Revised 27 July 2014 Accepted 28 July 2014 Published Online First 21 August 2014

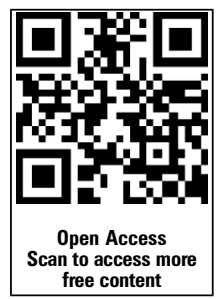

CrossMark

To cite: Zakeri N, Coda S, Webster S, et al. Frontline Gastroenterology

2015:6:270-277.

\begin{abstract}
Objective Conscious sedation is widely used in endoscopic practice but is not without risk. We aimed to determine the frequency of sedation complications requiring reversal, and to identify potential patient and procedural risk factors.

Design A retrospective study of all gastrointestinal endoscopic procedures performed under conscious sedation, in a large three-campus tertiary referral endoscopic centre, between 12 October 2007 and 31 December 2012 ( $n=52$ 553). Flumazenil or naloxone administration was used as a marker of sedation complications requiring reversal. Reversal cases were analysed for associations with sedation dose, patient American Society of

Anesthesiologists (ASA) grade, age and type of procedure undertaken.
\end{abstract}

Results In total, 149 sedation reversals occurred, representing $0.28 \%$ of all sedated endoscopic procedures carried out. Endoscopic Retrograde Cholangiopancreatography (ERCP) and increasing patient ASA grade were positively associated with sedation reversal $(p<0.05)$. Mean midazolam dose was highest for ERCP (4.9 $\pm 2.9 \mathrm{mg}$ ) and lowest for flexible sigmoidoscopy (1.7 $\pm 0.6 \mathrm{mg} ; \mathrm{p}<0.01)$. Mean opioid dose (calculated as pethidine equivalent) was highest for ERCP $(62.9 \pm 38.7 \mathrm{mg})$ and lowest for gastroscopy $(6.9 \pm 13.5 \mathrm{mg} ; \mathrm{p}<0.01)$. Maximum doses of midazolam or opioid recommended by the British Society of Gastroenterology were exceeded in $7.4 \%$ and $14.1 \%$ of reversals, respectively.

Conclusions ERCP procedures and higher patient ASA grade were associated with an increased risk of conscious sedation-related complications requiring reversal. In these highrisk groups, alternative sedation strategies should be considered and tested. Prospective studies are needed to further explore risk factors that may help predict adverse sedation outcomes.

\section{INTRODUCTION}

While sedation plays an integral role in endoscopic practice, it is not without risk. Most gastrointestinal (GI) endoscopic procedures are performed under 'conscious sedation', a drug-induced depression of consciousness during which patients are able to maintain purposeful responses to verbal or tactile stimulation, and cardiorespiratory function remains intact. $^{1}$

Over the past decade, there has been a significant increase in awareness of the potential hazards of endoscopic sedation. Synergistic action between benzodiazepines and opioids further increases this risk. In a nationwide study from the USA, 96.9\% of all endoscopic procedures were performed under conscious sedation. Complications occurred in $1.4 \%$ of cases, of which $0.9 \%$ were cardiorespiratory events. ${ }^{2}$ Safe sedation guidelines produced by the British Society of Gastroenterology (BSG) and the American Society for Gastrointestinal Endoscopy highlight the need for accurate patient risk stratification, close procedural monitoring and minimisation of sedation doses. ${ }^{3} 4$

A UK National Confidential Enquiry into Patient Outcome and Death (2004) evaluated inpatient deaths occurring within 30 days of therapeutic GI endoscopic procedures. In $14 \%$ of cases, the sedation doses were judged to be inappropriate. ${ }^{5}$ Serious harm or death resulting from midazolam or opioid overdose during conscious sedation is now a UK Department of Health 'Never Event' (2012-2013). ${ }^{6}$

Establishing risk factors to help predict adverse responses to conscious sedation may help reduce the incidence of 
sedation-related complications. In this study, we retrospectively analysed GI endoscopic procedures performed under conscious sedation (midazolam \pm opioid) over a 5 -year period. Our objective was to assess the frequency of sedation complications requiring reversal, and to identify potential patient and procedure related risk factors.

\section{METHODS}

\section{Study population}

Imperial College Healthcare NHS Trust, London, UK, comprises a large three-campus tertiary referral endoscopic centre, with an estimated catchment population of $650000 .^{7}$ The three endoscopic units based at Charing Cross, St Mary's and Hammersmith hospitals, undertake around 17000 endoscopic procedures per annum. ${ }^{7}$ We performed a retrospective analysis of endoscopic procedures carried out in the Trust between 12 October 2007 and 31 December 2012. All endoscopic procedures performed under conscious sedation (midazolam \pm opioid), excluding propofol administration, were included in the study. We compared our results with a previous two-site Trust audit conducted by our group between 1 January 2000 and 31 December 2005 (unpublished data).

\section{Endoscopic data collection}

The Trust endoscopy reporting software and database system 'Scorpio' (Ascribe, UK), was analysed to identify all sedation reversal events that occurred between 12 October 2007 and 31 December 2012. Flumazenil or naloxone administration was used as a marker of sedation complications requiring reversal treatment. Only reversal events that occurred during or immediately after the procedure, in the endoscopy room, were included in our study.

\section{Patient and procedure related risk factors for sedation reversals}

The endoscopic records for all patients who received sedation reversal drugs, flumazenil or naloxone, during their endoscopic procedure were analysed to identify patient age, the documented American Society of Anesthesiologists (ASA) grade, type of procedure undertaken, type of sedation used and the total doses of midazolam \pm opioids administered.

All opioid doses were converted to pethidine equivalent doses to allow comparison. We note that there are differences in the literature regarding opioid conversion ratios and the published experience is limited. We used the conversion ratio of $100 \mu \mathrm{g}$ fentanyl being approximately equivalent to $75 \mathrm{mg}$ pethidine based on their equivalent analgesic activity, and $1 \mathrm{mg}$ alfentanil being approximately equivalent to $150 \mathrm{mg}$ pethidine. $^{8-11}$ Conversion calculations are detailed in online supplementary appendix 1 .
30 day mortality rate following endoscopic procedures

All cases where patients died within 30 days of their endoscopic procedure were identified. Individual case notes for these patients were obtained from medical records to assess the rationale for the endoscopy, type and doses of sedation used, documented reason for sedation reversal, the patient's medical history, ASA grade, and whether the sedation used during the endoscopic procedure may potentially have contributed to the mortality.

\section{Statistical analysis}

Results were expressed as mean $\pm \mathrm{SD}$ for continuous variables and frequency (\%) for categorical variables. Statistical analysis was carried out using $\chi^{2}$ test and the linear regression model. All tests were performed using Origin (OriginLab Corporation, USA). In all cases, the null hypothesis tested was that there was no association between the variables, and a $\mathrm{p}$ value of $<0.05$ was considered statistically significant.

\section{RESULTS}

A total of 73989 endoscopic procedures were performed across the three endoscopic units over the study period. Conscious sedation (midazolam \pm opioid) was used in 52553 procedures. Flumazenil or naloxone was required in 149 endoscopic cases, representing $0.28 \%$ of all sedated endoscopic procedures carried out. This was comparable with our previous audit, 2000-2005, with a sedation reversal rate of $0.27 \%$. No significant difference was noted in the overall sedation reversal rate between the two study periods $(0.28 \%$ vs $0.27 \%$; $>>0.79)$.

Endoscopic Retrograde Cholangiopancreatography (ERCP) was the procedure type most commonly associated with sedation reversal, with a sedation reversal rate of $1.0 \%(\mathrm{p}<0.05)$ (figure 1A). This was followed by enteroscopy $(0.40 \%$ reversal rate), gastroscopy $(0.27 \%)$, colonoscopy $(0.22 \%)$, flexible sigmoidoscopy $(0.21 \%)$ and endoscopic ultrasound $(0.09 \%)$.

Patient demographics for sedation reversal events are presented in table 1 . There was a positive association with sedation reversal and increasing patient ASA grade $(\mathrm{p}<0.05)$ (figure 1B). No significant association was found between patient age $(\leq$ or $>70$ years) and the frequency of sedation reversal events.

The mean dose of midazolam used in reversal events was $3.0 \mathrm{mg}$ (range $0.5-14 \mathrm{mg}$ ). The mean dose of midazolam varied by procedure type and was highest for ERCP $(4.9 \pm 2.9 \mathrm{mg})$ and lowest for flexible sigmoidoscopy $(1.7 \pm 0.6 \mathrm{mg} ; \mathrm{p}<0.01)$ (see online supplementary appendix 2). Midazolam doses exceeding $5 \mathrm{mg}$ were administered in $7.4 \%$ of reversal cases (11/149 procedures, nine of which were ERCP procedures).

Opioids were used in $55.7 \%$ of reversal cases (83/ 149 procedures) and included pethidine, fentanyl or alfentanyl. All opioid doses were converted to a 
A Sedation reversal and type of procedure

Bar graphs showing the association between the percentage of sedation reversal events and type of endoscopic procedure.

Sedation reversal

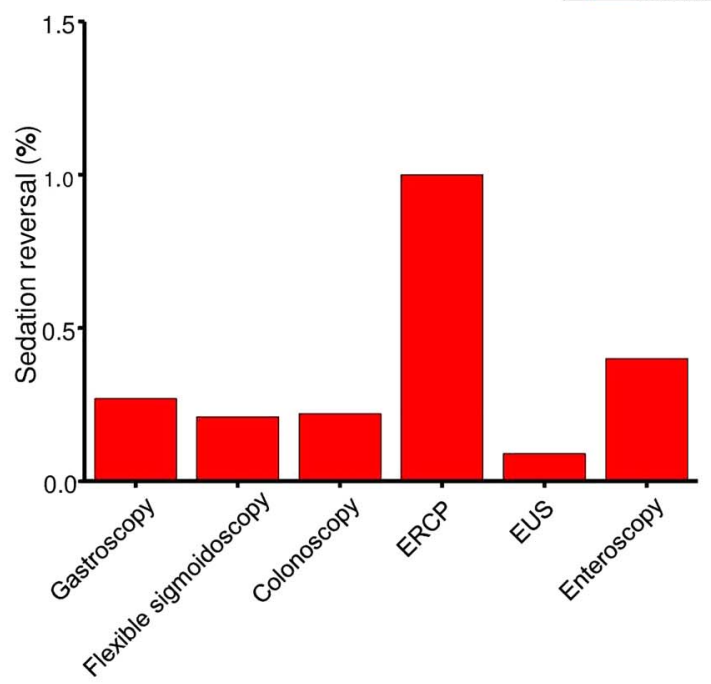

\section{B Sedation reversal rate and ASA grade}

Bar graphs showing the positive association between the percentage of sedation reversal events and patient ASA grade. ASA grade: (1) fit; (2) mild systemic; (3) severe systemic; (4) life-threatening systemic.

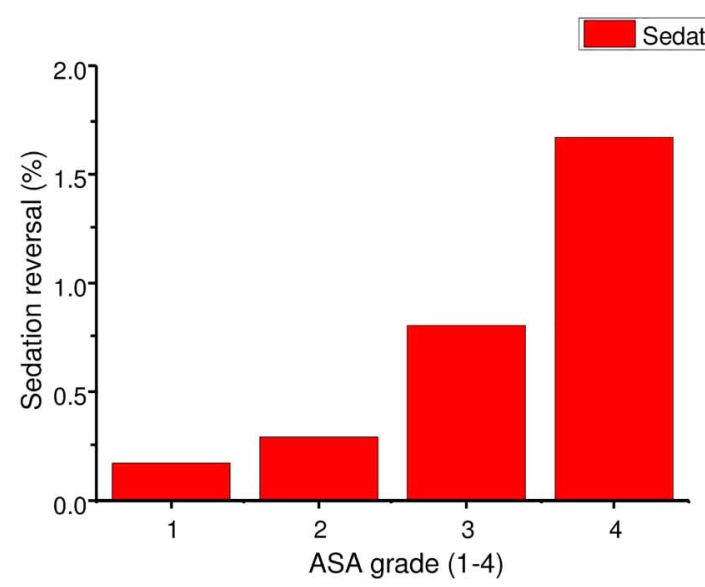

Figure 1 (A) Sedation reversal and type of procedure. Bar graph showing the association between the percentage of sedation reversal events and type of endoscopic procedure. (B) Sedation reversal rate and ASA grade. Bar graph showing the positive association between the percentage of sedation reversal events and patient ASA grade. ASA grade: (1) fit; (2) mild systemic; (3) severe systemic; (4) life-threatening systemic. ASA, American Society of Anesthesiologists; ERCP, endoscopic retrograde cholangiopancreatography; EUS, endoscopic ultrasound.

pethidine equivalent dose. The mean pethidine equivalent dose of opioid used was $47.9 \mathrm{mg}$ (range $12.5-150 \mathrm{mg})$. The mean dose of opioid varied according to the procedure-type and was highest for ERCP $(62.9 \pm 38.7 \mathrm{mg})$ and lowest for gastroscopy $(6.9 \pm 13.5 \mathrm{mg} ; \mathrm{p}<0.01) \quad$ (see online supplementary appendix 2). One enteroscopy procedure used a pethidine equivalent dose of $75 \mathrm{mg}$, however, given that this was the only enteroscopy reversal to occur, we have taken the highest statistically significant mean dose of opioid to remain for ERCP. Pethidine equivalent doses exceeding $50 \mathrm{mg}$ were administered in $25.3 \%$ of reversal cases where an opioid had been used (21/83 procedures, 18 of which were ERCP procedures), representing $14.1 \%$ of the total number of sedation reversal events.

No significant association was found between the mean dose of midazolam or opioid used in sedation reversal events and patient age ( $\leq$ or $>70$ years).

The main reasons for sedation reversal were: hypoxia, hypotension, bradycardia, a reduced level of responsiveness and risk of aspiration from food 
Table 1 Patient demographics in sedation-reversal events

\begin{tabular}{ll}
\hline Patient demographics & $\begin{array}{l}\text { Number of patients } \\
\text { (\% of total) }\end{array}$ \\
\hline Age & $79(53.0)$ \\
$\leq 70$ & $70(47.0)$ \\
$>70$ & \\
Sex & $66(44.3)$ \\
$\quad$ Male & $83(56.7)$ \\
Female & \\
ASA grade & $45(30.2)$ \\
1 Fit & $53(35.6)$ \\
2 Mild systemic disease & $43(28.9)$ \\
3 Severe systemic disease & $6(4.0)$ \\
4 Severe systemic disease with a constant & \\
$\quad$ Threat to life & $2(1.3)$ \\
Not specified &
\end{tabular}

ASA, American Society of Anesthesiologists. ${ }^{12}$

residue (table 2). In 56 procedures $(37.6 \%$ of reversal cases), the rationale for the use of reversal agents had not been specified.

Ten patients died within 30 days of their endoscopic procedure being carried out. These patients' case notes were obtained from the medical records department (under the Data Protection Act 1998). Details of the 10 cases are presented (table 3). Four patients underwent upper GI endoscopies for percutaneous endoscopic gastrostomy placement, three patients required ERCPs for stent insertion, and three upper GI endoscopies were performed for haematemesis or melaena. Interestingly, on more detailed analysis, we found that the ASA grades documented for five patients had been underestimated. Overall, seven out of the ten patients were deemed to be ASA Grade 3 (severe systemic illness) and three patients ASA Grade 4 (severe systemic illness with a constant threat to life). Although these patients all experienced sedationrelated complications requiring reversal, on review, the sedation did not appear to be a likely factor contributing to mortality.

Table 2 Documented rationale for sedation-reversal events

\begin{tabular}{lc}
\hline Indication for sedation reversal & $\begin{array}{l}\text { Number of reversal events } \\
\text { (\% of total) }\end{array}$ \\
\hline Hypoxia & $28(18.8)$ \\
Hypotension & $26(17.4)$ \\
Bradycardia & $1(0.7)$ \\
Respiratory depression & $2(1.3)$ \\
Reduced responsiveness & $24(16.1)$ \\
Risk of aspiration & $12(8.1)$ \\
Procedure abandoned due to poor & $2(1.3)$ \\
bowel preparation & \\
Patient discomfort/agitation & $2(1.3)$ \\
Drug induced ileus & $1(0.7)$ \\
Chest pain & $1(0.7)$ \\
Not specified & $56(37.6)$ \\
\hline
\end{tabular}

\section{DISCUSSION}

Conscious sedation remains the most commonly used endoscopic sedation strategy; improving patient comfort and overall endoscopist satisfaction. ${ }^{13}$ With increasing numbers of endoscopic procedures performed each year, patient safety is of vital importance. Serious harm or death resulting from midazolam or opioid overdose during conscious sedation is now a UK Department of Heath 'Never Event'. ${ }^{6}$ However, data reporting endoscopic sedation-related complications varies widely, and few studies have explored the risk factors behind these adverse events. In this study, we focus on sedation-related complications significant enough to necessitate sedation reversal.

To the best of our knowledge, only one previously published study has specifically examined predictive factors for reversal agent use in GI endoscopy, however, this study from the USA was confined to ERCP procedures only. ${ }^{14}$ Our study is the first to examine sedation reversal events in detail across the full spectrum of GI endoscopic procedure types. We also believe it to be the largest retrospective study of endoscopic sedation reversal events in Europe. Our 5 -year analysis, across a three-campus tertiary referral endoscopic centre, has revealed a subset of patients and procedures that may carry an increased risk of developing sedation-related complications requiring reversal. Identifying such risk factors may enable more accurate risk stratification prior to endoscopy and allow consideration, where necessary, of alternative sedation techniques.

First, our results suggest that patients with a higher ASA grade may be more likely to incur sedationrelated complications requiring reversal. In support of this, a review of 324737 endoscopic procedures by Sharma et al reported higher ASA grades to be a significant independent risk factor for cardiorespiratory unplanned events. ${ }^{2}$ Old age ( $>60$ years) and inpatient status were also identified as potential patient risk factors for endoscopic cardiopulmonary complications. ${ }^{2}$ Since inpatients tend to be more unwell than outpatients, ASA grade may be a potential confounder for an inpatient association. Interestingly, in our study, we did not find a significant association between the frequency of sedation reversal events and patient age (less than vs greater than 70 years). We hypothesise that this may be due to more gradual increments of sedation being used in elderly patients, although prospective studies will be required to substantiate this.

Our data suggest that ERCP procedures may be associated with a higher rate of sedation complications requiring reversal compared with other endoscopic procedure types. Chawla et al reported the grade of difficulty of cannulation in ERCPs as a variable significantly associated with failure of gastroenterologist-directed conscious sedation. ${ }^{15}$ Furthermore, we found that ERCP procedures involved higher mean sedation doses. Despite synergistic effects between benzodiazepines and 
Table 3 Cases of mortality within 30 days of the endoscopic procedure

\begin{tabular}{|c|c|c|c|c|c|c|}
\hline $\begin{array}{l}\text { Procedure } \\
\text { type }\end{array}$ & $\begin{array}{l}\text { Patient } \\
\text { age } \\
\text { (years) }\end{array}$ & $\begin{array}{l}\text { Indication for } \\
\text { procedure }\end{array}$ & $\begin{array}{l}\text { ASA grade } \\
\text { documented }\end{array}$ & $\begin{array}{l}\text { Sedation } \\
\text { used }\end{array}$ & Reason for reversal & $\begin{array}{l}\text { Factors contributing to } \\
\text { mortality }\end{array}$ \\
\hline ERCP & 80 & Obstructive jaundice & Severe systemic & $\begin{array}{l}\text { Midazolam } \\
2 \mathrm{mg}, \text { Fentanyl } \\
75 \mu \mathrm{g}\end{array}$ & Persistent hypoxia & $\begin{array}{l}\text { Intracranial event, sepsis secondary } \\
\text { to pneumonia, acute renal failure }\end{array}$ \\
\hline OGD & 81 & Melaena & $\begin{array}{l}\text { Fit } \\
\text { (*Severe systemic) }\end{array}$ & $\begin{array}{l}\text { Midazolam } \\
1 \mathrm{mg}\end{array}$ & Hypotension & $\begin{array}{l}\text { Recurrent GI bleed with no bleeding } \\
\text { source identifiable. Pulmonary } \\
\text { oedema, aspiration pneumonia, } \\
\text { cellulitis }\end{array}$ \\
\hline ERCP & 59 & $\begin{array}{l}\text { Stent insertion } \\
\text { (pancreatic cancer with } \\
\text { gastric outlet } \\
\text { obstruction) }\end{array}$ & $\begin{array}{l}\text { Severe systemic } \\
\text { ( }{ }^{*} \text { Life-threatening) }\end{array}$ & $\begin{array}{l}\text { Midazolam } \\
3 \mathrm{mg} \text {, Fentanyl } \\
50 \mu \mathrm{g}\end{array}$ & $\begin{array}{l}\text { Deep sedation and food } \\
\text { residue in stomach (risk of } \\
\text { aspiration in recovery) }\end{array}$ & $\begin{array}{l}\text { Metastatic pancreatic } \\
\text { adenocarcinoma }\end{array}$ \\
\hline OGD & 85 & $\begin{array}{l}\text { PEG placement (unsafe } \\
\text { swallow) }\end{array}$ & Severe systemic & $\begin{array}{l}\text { Midazolam } \\
2 \mathrm{mg}\end{array}$ & $\begin{array}{l}\text { Hypoxia, reduced } \\
\text { responsiveness }\end{array}$ & $\begin{array}{l}\text { Aspiration pneumonia, acute } \\
\text { mesenteric ischaemia likely embolic } \\
\text { in origin secondary to AF }\end{array}$ \\
\hline ERCP & 45 & $\begin{array}{l}\text { CBD stricture, stent } \\
\text { insertion }\end{array}$ & $\begin{array}{l}\text { Severe systemic } \\
\text { ( }{ }^{*} \text { Life-threatening) }\end{array}$ & $\begin{array}{l}\text { Midazolam } \\
4 \mathrm{mg}, \text { Fentanyl } \\
50 \mu \mathrm{g}\end{array}$ & Low respiratory rate & $\begin{array}{l}\text { Advanced metastatic breast } \\
\text { carcinoma }\end{array}$ \\
\hline OGD & 66 & $\begin{array}{l}\text { PEG placement (unsafe } \\
\text { swallow) }\end{array}$ & $\begin{array}{l}\text { Mild systemic } \\
\text { (Severe systemic) }\end{array}$ & $\begin{array}{l}\text { Midazolam } \\
2 \mathrm{mg} \text {, Pethidine } \\
50 \mathrm{mg}\end{array}$ & $\begin{array}{l}\text { Reduced responsiveness, } \\
\text { not rousable } \\
\text { postprocedure }\end{array}$ & $\begin{array}{l}\text { Pneumonia, poor compliance with } \\
\text { treatment secondary to dementia }\end{array}$ \\
\hline OGD & 76 & Haematemesis & $\begin{array}{l}\text { Mild systemic } \\
\text { (*Life-threatening) }\end{array}$ & $\begin{array}{l}\text { Midazolam } \\
4 \mathrm{mg}\end{array}$ & $\begin{array}{l}\text { Food residue in stomach } \\
\text { (aspiration risk) }\end{array}$ & $\begin{array}{l}\text { Advanced metastatic oesophageal } \\
\text { cancer, persisting Gl bleed (patient } \\
\text { refused further intervention) }\end{array}$ \\
\hline OGD & 56 & PEG placement & Severe systemic & $\begin{array}{l}\text { Pethidine } \\
50 \mathrm{mg}\end{array}$ & $\begin{array}{l}\text { Reduced responsiveness } \\
\text { postprocedure }\end{array}$ & $\begin{array}{l}\text { HIV-associated progressive multifocal } \\
\text { leucoencephalopathy }\end{array}$ \\
\hline OGD & 86 & Melaena & Severe systemic & $\begin{array}{l}\text { Midazolam } \\
2.5 \mathrm{mg}\end{array}$ & Hypoxia & $\begin{array}{l}\text { GI bleed with no bleeding source } \\
\text { identifiable, pulmonary oedema, } \\
\text { worsening acute on chronic renal } \\
\text { failure }\end{array}$ \\
\hline OGD & 90 & PEG placement & Severe systemic & $\begin{array}{l}\text { Midazolam } \\
1 \mathrm{mg}\end{array}$ & Hypoxia & $\begin{array}{l}\text { Hospital-acquired pneumonia, } \\
\text { Clostridium difficile infection, Gl } \\
\text { bleeding, congestive cardiac failure }\end{array}$ \\
\hline
\end{tabular}

*Pre-endoscopy patient ASA grade deemed to be different after review of individual patient medical case notes.

ASA, American Society of Anesthesiologists; AF, atrial fibrillation; $C B D$, common bile duct; $E R C P$, endoscopic retrograde cholangiopancreatography;

$\mathrm{Gl}$, gastrointestinal; OGD, oesophago-gastro-duodenoscopy; PEG, percutaneous endoscopic gastrostomy.

opioids, higher doses of midazolam were frequently coupled with higher doses of opioids in ERCP procedures, providing a potential explanation for the increased rate of sedation complications in this group.

More than 48000 ERCP procedures are performed in the UK each year. ${ }^{16}$ Due to their complex and often prolonged nature, ERCP procedures tend to require sedation for longer periods of time, leading to higher total sedation doses compared with routine upper or lower GI endoscopy. In view of this, a number of studies have explored different sedation combinations for these higher risk procedures. ${ }^{14} 1718$

Propofol is a rapid-onset, short-acting anaesthetic agent used to achieve deep sedation. Its use in endoscopic procedures in the UK remains limited, requiring the presence of a trained anaesthetist due to an increased risk of respiratory depression. ${ }^{19}$ Routine use of propofol incurs greater staffing demands, procedure time and costs and is, therefore, unrealistic. However, increasingly, studies have shown that with appropriate caution, propofol may be an appropriate alternative sedation strategy for certain endoscopic procedures, particularly in high-risk groups. $^{1} 171820$

A systematic review of studies comparing conscious sedation with deep sedation (propofol) in ERCP procedures found no significant difference in sedationrelated complications between patient groups. Moreover, propofol administration was associated with faster patient recovery and higher patient satisfaction. ${ }^{18}$ Similarly, a randomised controlled trial comparing conscious sedation with propofol in highrisk patient groups (patients over the age of 80 years, with an ASA grade of 3 or above) found similar procedure tolerability in both groups, while propofol was associated with shorter recovery times and fewer oxygen desaturation events. ${ }^{20}$ This suggests that in select patients, propofol administration may be a safe and feasible option when administered by trained personnel.

The overall frequency of sedation complications necessitating reversal in our study was $0.28 \%$. 
By comparison, a study of 21011 endoscopic procedures by Arrowsmith et al reported serious cardiopulmonary complications in $0.54 \%$ of procedures using midazolam or diazepam. ${ }^{21}$ Sharma et $a l^{2}$ reported a complication rate of around $1.4 \%$ of endoscopic procedures performed under conscious sedation. Of note, our study only included endoscopic cases where sedation complications necessitated reversal, therefore, the total frequency of sedation-related complications, including those not significant enough to require reversal, is likely to be higher than $0.28 \%$.

The majority of sedation complications encountered in our study were cardiorespiratory events. In over a third of reversal cases, the specific nature of the complications necessitating reversal had not been documented on the endoscopy report. This information is valuable to help with future patient risk factor stratification and decisions regarding sedation strategies, therefore, more detailed documentation of sedation reversal events on endoscopic records should be provided.

The range of sedation doses used in our study was broad, with a midazolam dose range between 0.5 and $14 \mathrm{mg}$, and a pethidine equivalent dose range between 12.5 and $150 \mathrm{mg}$. The majority of endoscopic procedures requiring sedation reversal did not, however, involve excessively high sedation doses. Indeed, the mean dose of midazolam used in reversal events was $3.0 \mathrm{mg}$ and the mean opioid dose (pethidine equivalent) was $47.9 \mathrm{mg}$, both within the maximum recommended doses specified by BSG safe sedation guidelines (ie, midazolam $5 \mathrm{mg}$, pethidine $50 \mathrm{mg}$ ). ${ }^{3}$ Overall, higher doses of midazolam or opioid than those recommended by the BSG were used in a total of $7.4 \%$ and $14.1 \%$ of all reversal cases retrospectively; this predominantly occurring during ERCP procedures. Arrowsmith et $a l^{21}$ found that in all cases of cardiopulmonary complications, no patients had received more than $10 \mathrm{mg}$ midazolam. These observations suggest that sedation-related complications may still occur at relatively lower doses of sedation and may be influenced by multiple factors including ASA grade and a patient's inherent sensitivity to sedation, rather than by high sedation doses alone.

Our study is a retrospective analysis and is, therefore, limited by reliance on accurate documentation by endoscopists, particularly regarding the sedation doses given, the use of reversal agents and accurate patient ASA grade classifications. The ASA grades for five (out of 10) patients who died within 30 days of their procedure, had been underestimated, suggesting that ASA grades documented on endoscopy reports may not always have been accurately assessed prior to endoscopy. Only reversal agents administered in the endoscopy room were recorded in our study, therefore, any reversal events occurring postprocedure, in recovery areas, were not included.

Using endoscopy records retrospectively, the required data was not available to ascertain whether sedation increments or boluses had been given. We hypothesise that in some cases where complications occurred with low sedation doses, boluses of sedation may have been given rather than increments titrated to effect. We plan on investigating this further with prospective studies, comparing reversal rates in endoscopic procedures where sedation boluses versus increments are given.

Interestingly, no significant difference occurred in the frequency of sedation reversal events in our current study (2007-2012) compared with our previous audit (2000-2005). This is likely to be due, at least in part, to suboptimal adherence to sedation guidelines. Several published studies demonstrate that, in general, adherence to guidelines in clinical practice remains inadequate. A systematic review by McGlynn et $a l^{22}$ identified that patients in the USA received $54.9 \%$ of guideline-recommended care. Furthermore, a systematic review by Ebben et $a^{23}$ showed a wide variation of adherence to clinical guidelines, between $7.8 \%$ and $95 \%$ in a prehospital setting, and $0 \%$ and $98 \%$ in the emergency department. Responsible factors identified included lack of evidence or applicability, lack of knowledge of the recommendations and organisational constraints. $^{22} 23$

Despite the introduction of sedation guidelines emphasising patient stratification, we have shown that errors are persisting in assigning accurate ASA grades to patients prior to endoscopy. This may influence the degree of caution endoscopists apply to sedation. Furthermore, in view of resources restricting the use of deep sedation, we suspect that ERCP sedation practices have not significantly changed between the two study periods in our Trust. We, therefore, propose that more stringent preprocedural patient stratification, as well as more frequent application of anaesthetist-supported deep sedation for ERCP procedures, may help to reduce our stationary sedation reversal rates. Additional tailored interventions are needed to improve awareness and adherence to sedation guidelines in our Trust.

In conclusion, to the best of our knowledge, this study is the first to examine sedation reversal events in detail across a full spectrum of GI endoscopic procedure types. Our data suggest that ERCP procedures and higher patient ASA grade may help predict an increased risk of conscious sedation-related complications requiring reversal. In these high-risk groups, alternative sedation strategies should be considered. Well-powered prospective studies are needed to compare the use of propofol to conscious sedation in ERCP procedures and patients with higher ASA grades to assess for an impact on the frequency of sedation reversal events. Prospective studies are urgently awaited to explore and further determine potential risk factors in order to accurately predict adverse sedation outcomes. 


\section{Significance of the study}

\section{What is already known on this topic?}

- Endoscopic sedation-related complications remain a major concern.

- Serious harm or death resulting from midazolam or opioid overdose during conscious sedation is a UK Department of Health 'Never Event'.

- Safe sedation guidelines encourage patient risk stratification, close procedural monitoring and minimisation of sedation doses.

\section{What this study adds?}

- ERCP procedures and higher patient ASA grade appear to be associated with higher rates of conscious sedation-related complications requiring reversal.

- ERCP procedures appear to be associated with higher doses of both midazolam and opioids in sedation reversal events.

\section{How might it impact on clinical practice in the} foreseeable future?

- In prolonged therapeutic ERCP procedures and high risk patient groups, alternative sedation strategies, including the use of propofol, may help to reduce the frequency of adverse sedation events.

- Prospective studies are needed to further establish variables that may help predict adverse responses to conscious sedation in endoscopy.

Contributors NZ performed the data collection, data analysis, and drafted and revised the paper. NZ is the guarantor. SC performed all the statistical data analysis, contributed to data interpretation, and revised the draft paper. SW monitored data collection, contributed to data interpretation and revised the draft paper. WH contributed to data interpretation and revised the draft paper. AVT initiated the study, analysed the data and revised the draft paper.

\section{Competing interests None.}

Ethics approval Imperial College Healthcare NHS Trust Ethics Committee.

Provenance and peer review Not commissioned; externally peer reviewed.

Data sharing statement The authors will share the dataset analysed in this publication in accordance with 'The Data Protection Act 1998 and The Freedom of Information Act 2000' and 'The NHS as an Innovative Organisation:

Framework and Guidance on the Management of Intellectual Property in the NHS' to http://figshare.com/

Open Access This is an Open Access article distributed in accordance with the Creative Commons Attribution Non Commercial (CC BY-NC 4.0) license, which permits others to distribute, remix, adapt, build upon this work noncommercially, and license their derivative works on different terms, provided the original work is properly cited and the use is non-commercial. See: http://creativecommons.org/licenses/bync/4.0/

\section{REFERENCES}

1 Cohen LB, Delegge MH, Aisenberg J, et al. AGA Institute review of endoscopic sedation. Gastroenterology 2007;133:675-701.

2 Sharma VK, Nguyen CC, Crowell MD, et al. A national study of cardiopulmonary unplanned events after GI endoscopy. Gastrointest Endosc 2007;66:27-34.

3 Gastroenterology BSo. Guidelines on Safety and Sedation During Endoscopic Procedures 2003. http://www.bsg.org.uk/ clinical-guidelines/endoscopy/guidelines-on-safety-and-sedationduring-endoscopic-procedures.html (accessed Oct 2013).

4 Lichtenstein DR, Jagannath S, Baron TH, et al.; Standards of Practice Committee of the American Society for Gastrointestinal Endoscopy. Sedation and anesthesia in GI endoscopy. Gastrointestinal Endosc 2008;68:815-26.

5 NCEPOD. Scoping our pratice. The 2004 Report of the National Confidential Enquiry into Patient Outcome and Death 2004. http://www.ncepod.org.uk/pdf/2004/04sum.pdf (accessed Nov 2013).

6 Department of Health/Patient Safety and Investigations. The "Never Events" list 2012/13. https://www.gov.uk/government/ uploads/system/uploads/attachment_data/file/142013/Never_ events_201213.pdf (accessed Oct 2013).

7 Aspire to-a new set of values at Imperial College Healthcare NHS. http://www.nhsemployers.org/SharedLearning/Pages/ Aspireto-anewsetofvaluesatUmpericalCollegeHealthcare NHSTrust.aspx (accessed Oct 2013).

8 Society of Gastroenterology Nurses and Associates Inc. (SGNA). Meperidine (pethidine) Sedation Facts. http://www. sgna.org/issues/sedationfactsorg/medications/fentanyl.aspx (accessed Jul 2014).

9 Medsafe, New Zealand Medicines and Medical Devices Safety Authority. Fentanyl Data Sheet. http://www.medsafe.govt.nz/ profs/datasheet/f/fentanylbiomedinf.pdf (accessed Jul 2014).

10 O'Connor A, Schug SA, Cardwell H. A comparison of the efficacy and safety of morphine and pethidine as analgesia for suspected renal colic in emergency setting. J Accid Emerg Med 2000;17:261-4.

11 Wolverhampton and Dudley Palliative Medicine Physicians. Palliative Care: Opioid equianalgesic dose conversions. 2014. http://medicines.wolvespct.nhs.uk/formulary/documents/ Related_Documents/Opioid_Equianalgesic_Dose_Conversion. pdf (accessed Jul 2014).

12 American Society of Anesthesiologists. ASA Physical Status Classification System. http://www.asahq.org/Home/ForMembers/Clinical-Information/ASA-Physical-StatusClassification-System (accessed Feb 2014).

13 McQuaid KR, Laine L. A systematic review and meta-analysis of randomized, controlled trials of moderate sedation for routine endoscopic procedures. Gastrointest Endosc 2008;67:910-23.

14 Papachristou GI, Gleeson FC, Papachristou DJ, et al. Endoscopist administered sedation during ERCP: impact of chronic narcotic/ benzodiazepine use and predictive risk of reversal agent utilization. Am J Gastroenterol 2007;102:738-43.

15 Chawla S, Katz A, Attar BM, et al. Endoscopic retrograde cholangiopancreatography under moderate sedation and factors predicting need for anesthesiologist directed sedation: a county hospital experience. World J Gastrointest Endosc $2013 ; 5: 160-4$ 
16 Green JRB; The UK ERCP Stakeholders Working Party. The future of service and training in ERCP in the UK-A strategy. 2007. http://www.bsg.org.uk/pdf_word_docs/ercp_ stakeholders_08.doc (accessed Oct 2013).

17 Wehrmann T, Kokabpick S, Lembcke B, et al. Efficacy and safety of intravenous propofol sedation during routine ERCP: a prospective, controlled study [abstract]. Gastrointest Endosc 1999;49:677-83.

18 Garewal D, Powell S, Milan SJ, et al. Sedative techniques for endoscopic retrograde cholangiopancreatography. Cochrane Database Syst Rev 2012;6:CD007274.

19 Anaesthetists RCo. Raising the standard: a compendium of audit recipes. Recipe 9.8 'Endoscopy under sedation'. Audit Recipe Book, 2000.
20 Riphaus A, Stergiou N, Wehrmann T. Sedation with propofol for routine ERCP in high-risk octogenarians: a randomized, controlled study. Am J Gastroenterol 2005;100:1957-63.

21 Arrowsmith JB, Gerstman BB, Fleischer DE, et al. Results from the American Society for Gastrointestinal Endoscopy/U.S. Food and Drug Administration collaborative study on complication rates and drug use during gastrointestinal endoscopy. Gastrointest Endosc 1991;37:421-7.

22 McGlynn EA, Asch SM, Adams J, et al. The quality of health care delivered to adults in the United States. N Engl J Med 2003;348:2635-45.

23 Ebben RH, Vloet LC, Verhofstad MH, et al. Adherence to guidelines and protocols in the prehospital and emergency care setting: a systematic review. Scand J Trauma Resusc Emerg Med 2013;21:9. 